\title{
Evaluation of the Resistance in Gherkin (Cucumis anguria L.) to Fusarium Wilt and Inheritance of the Resistant Gene
}

\author{
Yuichi Matsumoto $^{1} \&$ Makoto Miyagi ${ }^{2}$ \\ ${ }^{1}$ United Graduate School of Agricultural Science, Tokyo University of Agriculture and Technology, Tokyo, Japan \\ ${ }^{2}$ Plant Biotechnology Institute, Ibaraki Agricultural Center, Ibaraki, Japan \\ Correspondence: Yuichi Matsumoto, Plant Biotechnology Institute, Ibaraki Agricultural Center, Ibaraki \\ 319-0292, Japan. Tel: 81-299-458-330. E-mail: yu-matsumoto@agri.pref.ibaraki.jp
}

Received: April 20, 2012 Accepted: June 20, 2012 Online Published: August 8, 2012

doi:10.5539/jas.v4n9p145 URL: http://dx.doi.org/10.5539/jas.v4n9p145

\begin{abstract}
To breed gherkin cultivars with resistance to fusarium wilt, caused by Fusarium oxysporum f. sp. melonis, information about resistance and its of inheritance is necessary. Of the races of Fusarium oxysporum $\mathrm{f}$. sp. melonis, race 2 is most prevalent and has been recognized since the 1930s in the United States. In this study, twenty three gherkin accessions were inoculated with Fusarium oxysporum f. sp. melonis race 2. Only one accession, PI 282442, showed resistance; all others were susceptible. In the $\mathrm{F}_{1}$ generation from the cross PI $282442 \times$ PI 320052 (susceptible) all plants were susceptible. The $F_{2}$ fits well the ratio 1 (resistant): 3 (susceptible). In the $\mathrm{BC}_{1} \mathrm{~F}_{1}$ generation $\left(\mathrm{F}_{1} \times \mathrm{PI} 282442\right), 14$ plants were resistant and 16 were susceptible, a ratio

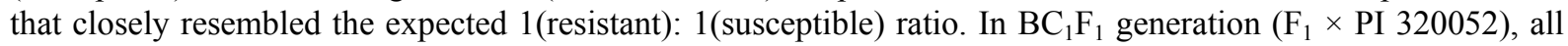
30 plants were susceptible. These results suggest that a single recessive gene controls resistance.
\end{abstract}

Keywords: gherkin, maxixe, fusarium wilt, disease severity, inheritance

\section{Introducation}

Gherkin (Cucumis anguria L.), also known as 'West Indian Gherkin', 'Burr Gherkin', and 'Maxixe', belongs to the subgenus Melo, which includes the melon (Cucumis melo L.) (Kirkbride, 1993). It is mainly cultivated in Brazil and the United States (Mangan et al., 2008). Gherkin fruits are consumed boiled, fried, stewed, or used fresh in salads. They are a valuable source of vitamins and minerals (Resende, 1998). Susceptibility and also resistance of gherkin to melon diseases such as powdery mildew (Lebeda, 1984; Alvarez et al., 2005) and fusarium wilt (Alvarez et al., 2005; Matsumoto et al., 2011) have been reported. Fusarium wilt is the most severe of these diseases; once the fungi colonizes a field, it survives in the soil. Crop residues and roots of most crops grown in rotation increase these persistent pathogenic populations (Banihashemi \& Dezeeuw, 1975). It is caused by Fusarium oxysporum f. sp. melonis, and divided into four physiological races $(0,1,2$, and 1,2) based on the pathogenicity on a set of differential genotypes (Risser et al., 1976). Of these, race 2 is most prevalent and has been recognized since the 1930s in the United States (Zuniga et al., 1997). Therefore, control of this race is most important for gherkin cultivation. Generally, resistant cultivars are effective in controlling soil-borne diseases. To date, no gherkin cultivars with resistance to fusarium wilt have been reported, although high-yield cultivars have been developed through cross breeding (Modolo \& Costa, 2004). To breed new gherkin cultivars with resistance to these races, information about resistant genetic resources and the mode of inheritance of resistance is necessary.

In this study, we evaluated the resistance/susceptibility of 23 accessions of gherkin to Fusarium oxysporum f. sp. melonis race 2, and investigated the mode of inheritance of the resistance.

\section{Method}

\subsection{Fungal Strain and Plant Materials}

The fungal strain used for inoculation, JCM 9288, was classified as race 2 (Namiki et al., 1998). A total of 23 gherkin accessions were used for this experiment (Table 1). Accessions were obtained from the National Germplasm Resources Laboratory (USDA, Agricultural Research Service, Beltsville, Maryland, USA). Three different melon cultivars, 'Charentais T', 'Doublon', and 'CM 17187', were used for race confirmation of the fungal strain JCM 9288. These cultivars were obtained from the Institut National de la Recherche Agronomique, 
France.

\subsection{Artificial Inoculation}

Inoculation was conducted using a root dip method (Matsumoto et al., 2011). The fungal strain JCM 9288 was cultured in $100 \mathrm{~mL}$ potato dextrose broth (PDB) in 300-mL flasks on a rotary shaker (ca. $120 \mathrm{rpm}$ ) for one week at $25^{\circ} \mathrm{C}$. The culture was then passed through two-ply gauze. The spore concentration, determined using a hemocytometer, was adjusted to the appropriate density $\left(10^{7}\right.$ spores $\left./ \mathrm{mL}\right)$ by dilution with sterile distilled water. For artificial inoculation, seeds of the tested plants were sown into sterilized garden soil in plastic trays and subsequently grown in a growth chamber at $26-30^{\circ} \mathrm{C}$. Seedlings with a fully expanded first true leaf were removed from the soil. Their roots were washed in tap water and dipped in the conidial suspension for $15 \mathrm{~s}$. Inoculated seedlings were then transplanted to the sterilized garden soil in new plastic pots and cultivated in a growth chamber at $23^{\circ} \mathrm{C}(16 \mathrm{~h}$ photoperiod).

\subsection{Evaluation of Disease Severity}

Disease severity was evaluated 21 days after inoculation according to a $0-3$ scale $(0=$ no symptoms, $1=$ small lesions on leaves, 2 = leaves strongly affected, and 3 = plant death). A total of 10-20 plants were evaluated for each accession or cultivar. Results were expressed as mean values and standard errors. Disease severity was log-transformed and data were analyzed using least-squares analysis of variance (ANOVA). A post hoc Tukey-HSD test was performed to compare disease severity among the accessions. For these analyses, JMP statistical software (ver. 9.0.0; SAS Institute Inc., Cary, NC, USA) was used.

\subsection{Mode of Inheritance of Resistance}

Two accessions were selected as parent lines: PI 282442 as the resistant accession and PI 320052 as the susceptible accession. A total of $15 \mathrm{~F}_{1}(\mathrm{PI} 282442 \times \mathrm{PI} 320052), 65 \mathrm{~F}_{2}(\mathrm{PI} 282442 \times \mathrm{PI} 320052), 30 \mathrm{BC}_{1} \mathrm{~F}_{1}\left(\mathrm{~F}_{1} \times\right.$ PI 282442), and $30 \mathrm{BC}_{1} \mathrm{~F}_{1}\left(\mathrm{~F}_{1} \times\right.$ PI 320052) plants were inoculated with the fungal strain JCM 9288. Individual plants were scored for disease severity on a $0-3$ scale, and plants scored 0 were considered resistant while those scored 1, 2, or 3 were considered susceptible. The observed ratios in the segregated $\mathrm{F}_{2}$ and $\mathrm{BC}_{1} \mathrm{~F}_{1}$ populations were tested for deviations from the expected ratios using the chi-square goodness of fit test, with a significance level of $P>0.05$.

\section{Results}

\subsection{Evaluation of Disease Severity}

Although all 'Charentais T' and 'CM 17187' seedlings died and the mean disease severity was 3.0, all 'Doublon' seedlings were asymptomatic and the mean disease severity was 0 . According to previous reports, 'Charentais T' is susceptible to all races, 'Doublon' has high resistance to races 0 and 2, and 'CM 17187' has high resistance to races 0 and 1 (Risser et al., 1976). Therefore, the fungal strain JCM 9288 was confirmed as race 2 from the pathogenicity of the inoculated plants. Next, the disease severity of each gherkin accession exposed to race 2 JCM 9288 was evaluated. Significant responses were detected in the gherkin accessions by ANOVA $\left(F_{22,252}=\right.$ $10.66, p<0.01$ ). When gherkin accessions were inoculated with race 2 JCM 9288, most accessions showed severe disease. In particular, the mean disease severity of PI 320052, PI 364475, PI 390449, PI 438678, PI 438679, and Ames 23548 was 3.0, and these were classified as highly susceptible. On the other hand, the PI 282442 score was significantly lower than that of most other accessions. The mean disease severity score was 0 , and it was classified as resistant (Figure 1).

\subsection{Mode of Inheritance}

To investigate the mode of inheritance of resistance to race 2, two accessions, PI 282442 and PI 320052, and $\mathrm{F}_{1}$, $\mathrm{F}_{2}$, and $\mathrm{BC}_{1} \mathrm{~F}_{1}$ plants were inoculated with the fungus. All 50 PI 282442 plants showed resistance and all 50 PI 320052 plants were susceptible. In the $F_{1}$ plants, all 50 plants were susceptible. In the $F_{2}$ plants, segregation resistance/susceptibility was observed. A total of 14 plants were resistant and 51 plants were susceptible. The observed segregation fits well to the expected 1 (resistant): 3 (susceptible) ratio $\left(\chi^{2}=0.42 ; P=0.51\right.$ ). In the $\mathrm{BC}_{1} \mathrm{~F}_{1}$ plants arising from a cross between $\mathrm{F}_{1}$ and PI 282442, segregation resistance/susceptibility was also observed. A total of 14 plants were resistant and 16 were susceptible. The chi-square goodness of fit test showed the expected 1 (resistant): 1 (susceptible) ratio $\left(\chi^{2}=0.13 ; P=0.72\right.$ ). In the $\mathrm{BC}_{1} \mathrm{~F}_{1}$ plants arising from a cross between $F_{1}$ and PI 320052, all 30 plants were susceptible (Table 2). These results suggest that there is a single recessive gene for resistance to Fusarium oxysporum f. sp. melonis race 2. 
Table 1. Accessions of gherkin used for the evaluation of the response to Fusarium oxysporum f. sp. melonis race 2

\begin{tabular}{lll}
\hline Accession number & Origin $^{\mathrm{a}}$ & Plant name $^{\mathrm{a}}$ \\
\hline PI 147065 & Brazil & - \\
PI 249896 & Zambia & Clark156 \\
PI 249897 & Namibia & Jensen \\
PI 282442 & Zimbabwe & - \\
PI 320052 & Ethiopia & - \\
PI 364475 & South Africa & 1441 \\
PI 390449 & Ecuador & W-C1000 \\
PI 438570 & Guatemala & W-C2445 \\
PI 438678 & Mexico & W-C2360 \\
PI 438679 & Mexico & W-C2337 \\
PI 482383 & Zimbabwe & Machacha \\
PI 482386 & Zimbabwe & TGR212 \\
PI 482387 & Zimbabwe & TGR235 \\
PI 482392 & Zimbabwe & TGR1928 \\
PI 494824 & Zambia & ZFA3310 \\
PI 512091 & Mexico & Meloncillo \\
PI 542135 & Botswana & 605 \\
Ames 22076 & Zambia & Moss888 \\
Ames 23536 & South Africa & JEWM005 \\
Ames 23541 & South Africa & JEWM016 \\
Ames 23548 & South Africa & JEWM033 \\
Ames 23550 & South Africa & JEWM036 \\
Ames 23589 & South Africa & JEWM110 \\
\hline
\end{tabular}

${ }^{a}$ Origins and plant names were according to the National Germplasm Resources Laboratory (USDA) database (http://www.ars-grin.gov/npgs/).

Table 2. Segregation of Fusarium oxysporum $\mathrm{f}$. sp. melonis race 2 resistence in $\mathrm{F}_{1}, \mathrm{BC}_{1} \mathrm{~F}_{1}$, and $\mathrm{F}_{2}$ segregation populations of PI 282442 and PI 320052

\begin{tabular}{llllll}
\hline \multirow{2}{*}{ Accession or cross combinations } & \multicolumn{2}{l}{ Number of plants $^{2}$} & $\begin{array}{l}\text { Expected } \\
\text { segregation } \\
\text { friquency }\end{array}$ & $\chi^{2}$ & $P$ value \\
\cline { 2 - 5 } & Resistance $^{\mathrm{a}}$ & Susceptible $^{\mathrm{a}}$ & $1: 0$ & - & - \\
\hline PI 282442 & 50 & 0 & $0: 1$ & - & - \\
PI 320052 & 0 & 50 & $1: 0$ & - & - \\
$\mathrm{F}_{1}($ PI $282442 \times$ PI 320052) & 0 & 50 & $1: 3$ & 0.42 & 0.51 \\
$\mathrm{~F}_{2}($ PI $282442 \times$ PI 320052) & 14 & 51 & $7: 9$ & 13.03 & $<0.01$ \\
& & & $1: 1$ & 0.13 & 0.72 \\
$\mathrm{BC}_{1} \mathrm{~F}_{1}\left(\mathrm{~F}_{1} \times\right.$ PI 282442) & 14 & 16 & $0: 1$ & - & - \\
$\mathrm{BC}_{1} \mathrm{~F}_{1}\left(\mathrm{~F}_{1} \times\right.$ PI 320052) & 0 & 30 & & & \\
\hline
\end{tabular}

${ }^{a}$ Resistance: disease severity score $=0$, Susceptible: disease severity score $=1,2$ or 3 .

${ }^{\mathrm{b}}$ Resistance: Susceptible. 




Figure 1. Response of the gherkin accessions to Fusarium oxysporum f. sp. melonis race 2. Accessions with different letters are significantly different (Bonferroni multiple comparison $t$ test following ANOVA, $P<0.05$ )

\section{Discussion}

Little information is available about the resistance of gherkin to fusarium wilt. A previous report described one gherkin accession that showed resistance to fusarium wilt. However, only two accessions were evaluated in that study and the name of the resistant accession was not reported (Alvarez et al., 2005). Our study revealed that accession PI 282442 is resistant to Fusarium oxysporum f. sp. melonis race 2, and the inheritance mode of the resistance is single recessive. Therefore, this cultivar could be used as a resistant genetic resource for gherkin breeding.

In our previous report, 27 gherkin accessions were inoculated with race 1, 2 to which many accessions showed resistance (Matsumoto et al., 2011). In this study, many accessions showed susceptibility to race 2 . Therefore, gherkin may show a strong tendency for susceptibility to race 2 . Breeding for a resistant gherkin cultivar to race 2 is thus of great importance.

To breed a resistant cultivar using this accession, marker-assisted selection would be favorable due to its recessive inheritance, which will allow faster phenotypic selection. Recently, some gherkin molecular markers were developed (Matsumoto et al., 2012a; 2012b). The results from such experiments are expected to be useful for identifying molecular markers linked to this recessive gene.

\section{Acknowledgements}

We are grateful to Asc. Prof. Dr. Tsutomu Kuboyama, College of Agriculture, Ibaraki University, Japan, for his valuable technical advice.

\section{References}

Alvarez, J. M., González-Torres, R., Mallor, C., \& Gómez-Guillamón, M. L. (2005). Potential sources of resistance to Fusarium wilt and powdery mildew in melons. HortScience, 40, 1657-1660.

Banihashemi, Z., \& DeZeeuw, D. J. (1975). The behavior of Fusarium oxysporum f. sp. melonis in the presence and absence of host plants. Phytopathology, 65, 1212-1217. http://dx.doi.org/10.1094/Phyto-65-1212

Fraser, R. S. S. (1992). The genetics of plant-virus interactions: implications for plant breeding. Euphytica, 63, 175-185. http://dx.doi.org/10.1007/BF00023922

Kirkbride, Jr., J. H. (Ed.). (1993). Biosystematic monograph of the genus Cucumis (Cucurbitaceae). Parkway Publishers, Boone, North Carolina.

Lebeda, A. (1984). Screening of wild Cucumis species for resistance to cucumber powdery mildew (Erysiphe cichoracearum and Sphaerotheca fuliginea). Scientia Horticuturae, 24, 241-249. 
http://dx.doi.org/10.1016/0304-4238(84)90107-9

Mangan, F., Mendonça, R., Moreira, M., Nunes, S., Finger, F., Barros, Z., Galvão, H., Almeida, G., Silva, R. A., \& Anderson, M. (2008). Production and marketing of vegetables for the ethnic markets in the United States. Horticultura Brasileira, 26, 6-14. http://dx.doi.org/10.1590/S0102-05362008000100002

Matsumoto, Y., Ogawara, T., Miyagi, M., Watanabe, N., \& Kuboyama. T. (2011). Response of wild Cucumis species to inoculation with Fusarium oxysporum f. sp. melonis race 1,2y. Journal of the Japanese Society for Horticultural Science, 80, 414-419. http://dx.doi.org/10.2503/jjshs1.80.414

Matsumoto, Y., Watanabe, N., \& Kuboyama, T. (2012a) Cross-species transferability of 86 cucumber (Cucumis sativus L.) microsatellite markers to gherkin (C. anguria L.). Scientia Horticulturae, 136, 110-114. http://dx.doi.org/10.1016/j.scienta.2012.01.009

Matsumoto, Y., Watanabe, N., \& Kuboyama, T. (2012b) Cross-species amplification of 349 melon (Cucumis melo L.) microsatellites in gherkin (Cucumis anguria L.). Journal of Plant Breeding and Crop Science, 42, 25-31. http://dx.doi.org/10.5897/JPBCS11.090

Modolo, V. A., \& Costa, C. P. (2004). Gherkin elite line selection. Crop Breeding and Applied Biotechnology, 4, 63-67.

Namiki, F., Shiomi, T., Nishi, K., Kayamura, T., \& Tsuge, T. (1998). Pathogenic and genetic variation in the Japanese strains of Fusarium oxysporum f. sp. melonis. Phytopathology, 88, 804-810. http://dx.doi.org/10.1094/PHYTO.1998.88.8.804

Resende, G. M. (1998). Influence of planting dates on indian gherkin cultivar's yield. Horticultura Brasileira, 16, 167-171.

Risser, G., Banihashemi, Z., \& Davis, D. W. (1976). A proposed nomenclature of Fusarium oxysporum f. sp. melonis races and resistance genes in Cucumis melo. Phytopathology, 66, 1105-1106. http://dx.doi.org/10.1094/Phyto-66-1105

Zuniga, T. L., Zitter, T. A., Gordon, T. R., Schroeder, D. T., \& Okamoto, D. (1997). Characterization of pathogenic races of Fusarium oxysporum f. sp. melonis causing Fusarium wilt of melon in New York. Plant Disease, 81, 592-596. http://dx.doi.org/10.1094/PDIS.1997.81.6.592 